\title{
Urbanização e transformação dos sistemas indígenas de manejo de recursos naturais : o caso do alto rio Negro (Brasil)
}

\author{
Ludivine ELOY ${ }^{1} \&$ Cristiane LASMAR ${ }^{2}$
}

\begin{abstract}
RESUMO
O objetivo do artigo é analisar as transformações observadas nos sistemas indígenas de manejo dos recursos naturais no Alto Rio Negro, Noroeste Amazônico, devido à urbanização intensa e acelerada de algumas localidades e aos processos migratórios ocorridos nas últimas décadas. Nossos dados foram obtidos por meio de pesquisas etnográficas e agroeconômicas, associadas ao Sistema de Informação Geográficas para análise de população, direitos fundiários e paisagens na área periurbana de São Gabriel da Cachoeira, a principal cidade da regiáo. As comunidades indígenas utilizam um território tradicional, onde se articulam diversos tipos de direitos fundiários sobre os recursos naturais, desde o uso individual exclusivo até a propriedade comum. $\mathrm{Na}$ regiáo periurbana, a propriedade privada da terra se tornou dominante. No entanto, por causa da escassez crescente dos recursos naturais ao redor da cidade, as famílias migrantes negociam seus direitos fundiários no âmbito de uma rede social extensa, criando assim uma estratégia multilocal. Esta pode ser entendida como manifestação da adaptabilidade dos sistemas tradicionais de manejo dos recursos naturais.
\end{abstract}

PALAVRAS-CHAVE: propriedade coletiva, Terras Indigenas, urbanização, multilocalidade, Brasil.

\section{Urbanization and transformation of indigenous resource management: the case of upper Rio Negro (Brazil)}

\begin{abstract}
We analyse the transformations in indigenous resource management due to urbanization and migratory flows in the Upper Rio Negro, Northwest Amazon. Data were obtained from ethnographic and agro-economic research, combined with a GIS analysis of population, land tenure and landscape distribution in the peri-urban zone of São Gabriel da Cachoeira, the main town of the region. Each indigenous community is associated with a traditional territory, within which are articulated many kinds of resource use rights, ranging from individual exclusive ownership to common property. In the peri-urban area, private ownership has become the main land-use right. Due to the increasing scarcity of available resources around São Gabriel, newly arrived indigenous families have to negotiate land-use rights within their large kinship networks and to resort to a multilocal strategy. This multilocal land-use system may be seen as an expression of the adaptation of traditional natural resources management. KEYWORDS: common property; Indigenous Land; urbanization; multi-sited households, multilocal strategy; Brazil
\end{abstract}

\footnotetext{
1 Centre National de la Recherche Scientifique. E-mail: ludivine.eloy@univ-montp3.fr;

2 Universidade Federal do Rio de Janeiro E-mail:cristianelasmar@gmail.com
} 


\section{INTRODUÇÃO}

A constituição de 1988 promoveu a afirmação dos direitos territoriais e culturais dos povos indígenas do Brasil e permitiu aumentar significativamente o número e a extensão das Terras Indigenas na Amazônia. Nestas áreas, definidas como as "terras que tradicionalmente ocupam" (artigo 231), as populaçóes nativas ganham o direito de usufruto exclusivo e coletivo sobre os recursos naturais. No entanto, existe uma certa ambiguidade a respeito da relação entre estes direitos fundiários e o uso sustentável dos recursos naturais, sobretudo com as mudanças sociais, econômicas e culturais rápidas observadas em certas regióes da Amazônia (Redford e Stearman, 1993; Freire, 2003). De modo mais específico, tendo em vista a intensificação dos movimentos migratórios e a adoção de novas formas de vida nas cidades, devemos nos perguntar em que medida as populaçóes indígenas vêm adaptando seus sistemas de manejo dos recursos naturais.

Nas últimas décadas, assistimos a um notável processo de urbanização na Amazônia brasileira. Aproximadamente 70\% da população da região vive atualmente em áreas urbanas (Padoch et al. 2008). Ao mesmo tempo em que proliferam novas cidades de pequeno e médio porte, áreas periféricas de antigos e importantes centros urbanos se avolumam de maneira desordenada, mesmo em regióes relativamente afastadas das frentes pioneiras (Browder e Godfrey 1997). Nas Terras Indígenas, por exemplo, apesar do tamanho das aglomeraçóes populacionais na área periurbana ${ }^{1}$ e das taxas de desmatamento serem relativamente reduzidas, a sustentabilidade dos sistemas de manejo dos recursos naturais torna-se uma questáo de suma importância. Embora o sistema de parentesco ainda cumpra um importante papel como princípio de ordenamento das territorialidades indígenas (Cunha e Almeida, 2001; Andrello, 2006), em muitas dessas áreas o aumento da densidade demográfica e o jogo das relaçóes locais de poder criam situaçóes de competição por acesso e controle dos recursos naturais, sobretudo quando os programas públicos de regularização fundiária e de desenvovimento agrícola induzem a propriedade privada e desigualdades de acesso à terra. Essa situaçáo resulta muitas vezes em conflitos socioambientais (Eloy e Le Tourneau, 2009; Pereira et al. 2009; Sirén, 2007), mas é importante notar que a relevância dessa reflexão não se restringe ao âmbito do debate conservacionista. Trata-se de uma questão importante também para a afirmação das demandas dos grupos nativos da Amazônia, pois o mote do controle e da proteção dos recursos florestais dentro de áreas apropriadas coletivamente tem sido um pilar importante de suas estratégias políticas e comerciais (Albert, 2000).

$\mathrm{Na}$ América Latina, os sistemas tradicionais de manejo dos recursos naturais costumam se apoiar em direitos fundiários que articulam o regime de propriedade privada com regime de propriedade coletiva ${ }^{2}$ (Adams et al., 2006; Todedo et al. 2003; Alcorn et Toledo, 1998). Além disso, um ponto comum entre diferentes sociedades indígenas amazônicas é a dispersão espacial das unidades residenciais e produtivas, que gera uma forte mobilidade dos indivíduos, mas também a fluidez e a flexibilidade dos limites territoriais (Moreira, 2003; Pezzuti e Chaves, 2009). Estas caraterísticas resultam na complexidade e sobreposição espacial e temporal dos direitos fundiários, possuídos por diferentes coletivos, e relativos aos diferentes recursos existentes em uma mesma área. Por isso, a compreensão do processo de urbanização da Amazônia requer a análise criteriosa de processos socioespaciais locais (Padoch et al. 2008).

Do ponto de vista conceitual, é necessário que estejamos atentos à complexidade das transformaçôes em curso, que não se prestam a análises baseadas em dicotomias simplistas entre práticas tradicionais e práticas modernas (Ostrom et al, 1994). É fundamental focalizar as capacidades de inovação dos atores (ou adaptabilidade ${ }^{3}$ ) diante das transformaçóes ocorridas em seu ambiente. Numa perspectiva antropológica, trata-se de observar, em contextos específicos e locais, a apropriaçáo e re-significação de aspectos do mundo dos brancos por parte dos povos indígenas, a partir de suas lógicas culturais próprias (Sahlins, 1997).

Este artigo contribui para a compreensão destes processos na Amazônia Brasileira Ocidental. Analisamos as novas configuraçóes socioambientais resultantes do deslocamento de famílias indígenas originárias de comunidades ribeirinhas das Terras Indígenas do Alto Rio Negro em direção a Sáo Gabriel da Cachoeira, o principal pólo urbano da região. A nossa hipótese é que, ao longo do processo de urbanização, as famílias indígenas podem adaptar os sistemas de manejo por meio da mobilidade e da multilocalidade de suas residências e atividades entre cidade e floresta, mantendo as características fundamentais do seu regime de uso e apropriação dos recursos. No processo de ocupação e exploração de áreas peri-urbanas, estáo sendo criadas ali formas de apropriaçáo de recursos naturais alternativas às regras fundiárias oficiais baseadas na propriedade privada da terra. Nosso objetivo é demonstrar que, ao mesmo tempo em que se verifica uma tendência à individualização dos regimes de propriedade, observa-se por outro lado a adaptabilidade dos sistemas tradicionais de manejo dos recursos naturais.

\section{MATERIAL E MÉTODOS}

A regiāo do alto Rio Negro é habitada por uma população multiétnica, formada por grupos pertencentes às famílias lingüísticas Tukano Oriental, Aruak e Maku. Compreende cinco Terras Indígenas, homologadas em 1998: TI Médio Rio Negro I, TI Médio Rio Negro II, TI Rio Téa, TI Rio Apapóris, TI Alto Rio Negro. Ao todo, elas abrangem um território de $106.103 \mathrm{~km}^{2}$ de extensão. Trata-se de uma área militarizada, 
na fronteira com a Colômbia e a Venezuela (figura 1). A zona de estudo é a periferia da cidade de São Gabriel da Cachoeira, sede do município de mesmo nome. A cidade, que se situa a $900 \mathrm{~km}$ de Manaus, na margem esquerda do rio Negro, possui uma população de aproximadamente 15 mil habitantes, dos quais $80 \%$ se consideram "índios" (ISA/foirn, 2005). Os moradores da cidade e arredores vivenciam importantes transformaçóes em seu modo de vida, que se traduzem, sobretudo, por mudanças nos regimes de sociabilidade, nos padrôes residenciais, e nas estratégias para a exploração dos recursos naturais (Eloy e Lasmar, 2006). Embora a cidade propriamente dita esteja fora da área demarcada, a influência do processo de urbanização se espraia sobre as Terras Indígenas, configurando uma relação dinâmica entre os dois domínios. Por isso, antes de focalizarmos o caso da cidade, faz-se necessária uma descrição sumária do como se organizam as territorialidades na região do Alto Rio Negro, entendida esta como uma área cultural específica.

Os povos de língua Tukano e Aruak integram um sistema regional de trocas matrimoniais e de bens materiais. Uma série de semelhanças socioculturais levou Berta Ribeiro (1995) a sugerir a existência de uma "cultura rionegrina". Entre os grupos das famílias lingüísticas Tukano e Aruak vigoram a regra de exogamia matrimonial e o princípio de descendência patrilinear. Idealmente, o grupo local é composto por homens pertencentes a um mesmo clá (referidos na literatura como sibs) e suas esposas 'estrangeiras'. Os grupos locais (clãs ou porçóes de clás) distribuem-se ao longo dos rios de acordo com distinçóes hierárquicas. Aqueles de origem clânica superior habitam as partes baixas, mais piscosas, ao passo que os grupos de origem inferior costumam habitar as cabeceiras (Chernela 1993). Nas comunidades ribeirinhas, a economia é baseada principalmente nas atividades de agricultura de corte e queima, de pesca e de produção artesanal, com uma divisão tradicional do trabalho produtivo por sexo (Lasmar 2008). A produção agrícola confere às mulheres um papel de extrema relevância no sistema comunitário. Pode-se dizer que, ali, a identidade feminina está estreitamente associada à lida agrícola (HughJones 1979, Lasmar 2005). Como veremos mais adiante, na área periurbana, abrem-se às mulheres outras possibilidades de obtenção de prestígio (Lasmar, 2008). Estas novas possibilidades, associadas à diluição de laços comunitários, ao papel de destaque adquiridos pelas mercadorias no cotidiano das famílias e a transformaçóes na estrutura fundiária, criam uma nova configuração na qual o trabalho agrícola perde alguns de seus significados tradicionais.

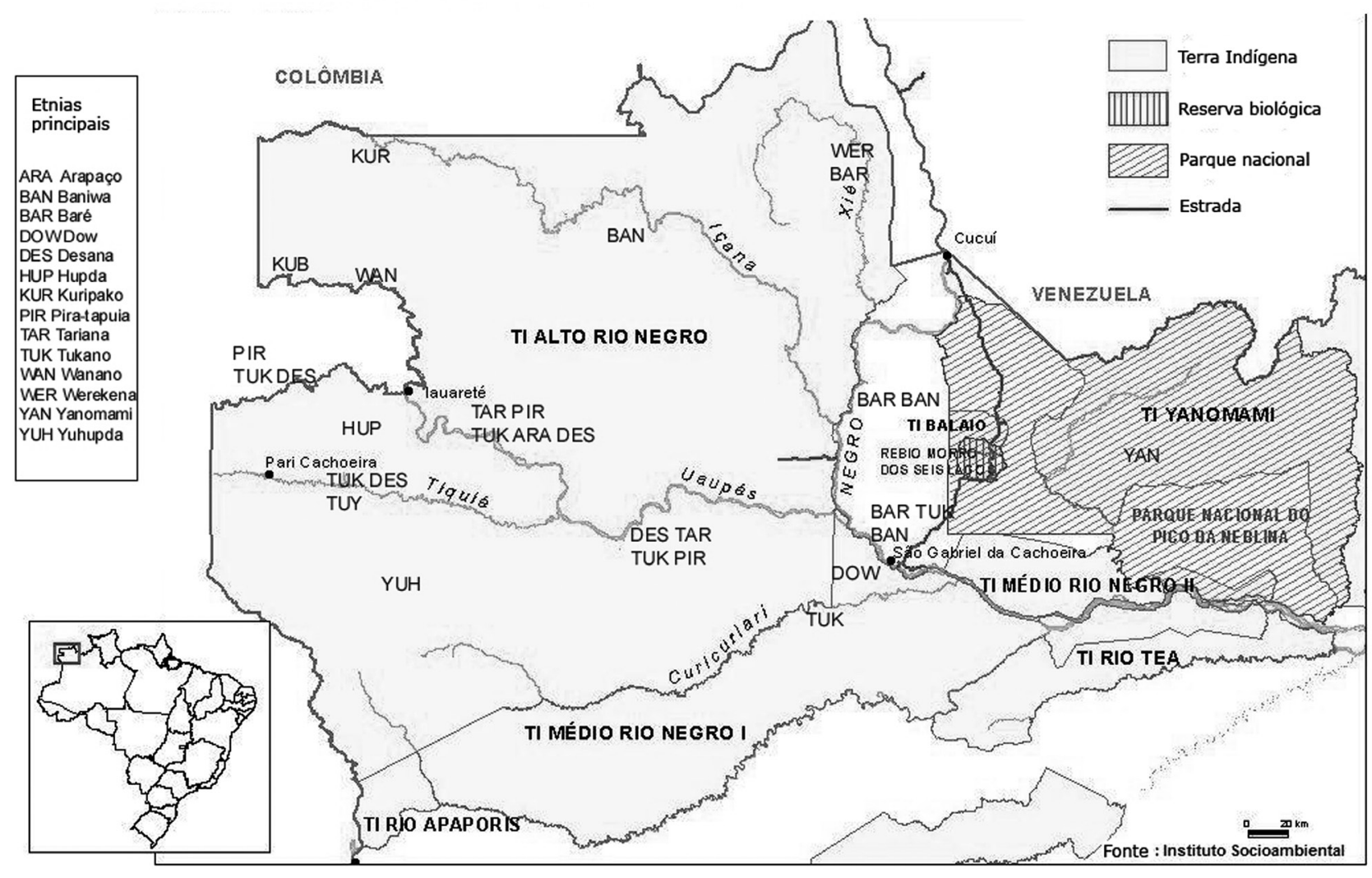

Figura 1 - Localização de São Gabriel da Cachoeira no Alto Rio Negro 
A nossa hipótese é que a adaptabilidade dos sistemas indígenas de manejo na área periurbana depende da complementaridade socioespacial dos modos de uso e apropriação dos espaços e recursos. Esta complementariedade é relacionada com sistemas de atividades complexos, que integram atividades produtivas, extrativistas e empregos remunerados (Toledo et al., 2003).

Nossos dados foram obtidos em três vertentes de pesquisa, realizadas entre 2003 e 2006. A primeira consistiu em uma investigação espacial da agricultura peri-urbana e das normas fundiárias por meio de leitura de paisagem, mapeamento participativo e sensoriamento remoto em imagens de satélite, complementado por levantamentos sistemáticos com GPS. Os dados foram compilados em Sistema de Informaçáo Geografico (Arcview 3.2), o que permitiu a produção de mapas temáticos.

A segunda vertente consistiu em entrevistas socioeconômicas sobre sistemas de produção, trajetória de migração, e formas de acesso e apropriação dos recursos naturais dos grupos familiares. Primeiramente, foi utilizada uma amostragem determinada pela localização do domicílio na zona de estudo $(\mathrm{n}=210)$. As entrevistas foram aprofundadas com 75 grupos domésticos, através de amostragem baseada em diversos parâmetros (etnia, origem, tempo de cidade, fonte de renda principal, local de moradia e de produção), com o objetivo de compor uma amostra heterogênea, que contemplasse situaçóes de vários tipos. Do total de entrevistas, 55\% foram realizadas com famílias residentes na cidade, e $45 \%$ nas comunidades periféricas. Contamos com um extenso corpo de dados estatísticos resultantes do Levantamento Socioeconômico e Demográfico da Cidade de Sáo Gabriel da Cachoeira (ISA/ FOIRN 2005).

Por fim, a análise foi enriquecida com os resultados de uma pesquisa etnográfica anterior (Lasmar 2005) sobre as transformaçôes ocorridas no modo de vida de famílias vindas das Terras Indígenas para residir em São Gabriel da Cachoeira.

\section{Uso e apropriação dos recursos naturais nas comunidades afastadas da cidade}

Nas comunidades atuais das Terras Indígenas, o padrão tradicional de moradia, em que todo o grupo local ocupava uma grande maloca, foi substituído por outro em que uma família nuclear (um casal e seus filhos solteiros ou recémcasados) ocupa uma casa relativamente menor. Os limites da comunidade são imprecisos e flexíveis. As áreas de plantio não costumam ser contínuas para uma mesma família, mas alternadas de acordo com os diversos nichos ambientais disponíveis, que são simultaneamente fontes de recursos alimentares, medicinais e combustíveis. Sendo a agricultura de tipo itinerante, e os recursos florestais e pesqueiros de disponibilidade sazonal, as famílias tendem a deslocar e/ou multiplicar suas casas, casas de forno e abrigos temporários (Meira, 1997). Além disso, os moradores indígenas da bacia do Rio Negro costumam percorer os rios e as florestas em inúmeras ocasióes, para utilizar certos recursos ou para visitar os parentes. Multilocalidade, mobilidade e redes extensas de troca são, portanto, características essenciais das territorialidades indígenas no Rio Negro.

O território de uma comunidade inclui áreas de posse dos grupos domésticos (roças, quintais e capoeira produtivas), áreas apropriadas pelos grupos patrilineares e patrilocais (capoeiras) e áreas de usufruto comum (floresta densa de terra firme, floresta alagável). Estas áreas são organizadas em mosaïco, sendo os quintais ao redor das casas, e as roças e capoeiras jovens distribuídas ao longo dos caminhos e igarapés. Quanto maior a proximidade de uma família de sua casa de moradia e de sua casa de forno, maior é a expressão de seus direitos individuais sobre o espaço físico. À medida que um indivíduo se vê compelido a afastar-se de suas casas e de suas roças, seus direitos individuais tendem a se diluir no conjunto das famílias da comunidade, ou das comunidades vizinhas.

No Rio Negro, os direitos coletivos envolvem regras de uso dos recursos naturais da área da comunidade, especialmente para produtos oriundos dos rios e da floresta densa. A incorporação de um novo membro numa comunidade, seja pelos vínculos patrilineares, seja pelo casamento (Lasmar 2008), possibilita o usufruto de bens, recursos e oportunidades presentes no território comunitário. Por outro lado, implica a participação em um regime de trabalho coletivo. Assim, caso uma família não pratique mais a agricultura e/ou resida boa parte do tempo na cidade, a estabilidade de seu vínculo de pertencimento passa a depender de sua participaçáo na vida social da comunidade (eventos coletivos, cultos religiosos, trabalhos comunitários, festas, etc). Geralmente, ela pode usufruir dos recursos florestais, mas é submetida a regras coletivas de uso, ou seja, a exploraçáo deve ser feita dentro de um certo limite de volume/valor e para uma exploraçáo principalmente não comercial. É comum que, nesses casos, as famílias continuem cuidando da sua área de árvores frutíferas no centro da comunidade, herdada dos pais e avós. Elas podem também confiar suas capoeiras e árvores frutíferas a outros moradores, em troca de serviços e/ou produtos. Veremos que esta flexibilidade tem um papel muito importante nas comunidades periurbanas, pois propicia a mobilidade dos indivíduos entre cidade e floresta.

\section{A ocupação da área periurbana}

Embora concentre mais de $40 \%$ de uma populaçáo municipal de aproximadamente 35 mil habitantes, a cidade de São Gabriel da Cachoeira não é o único aglomerado populacional do Alto Rio Negro. Entre 1996 e 2003, ao crescimento de $32,5 \%$ da população da cidade, correspondeu um crescimento de $12 \%$ da população residente na área 
periurbana. Em meio aos cerca de 700 comunidades e sítios que se espalham pela faixa ribeirinha, contamos cinco grandes povoaçôes: Assunção do Içana, Taracuá, Pari Cachoeira, Iauareté e Cucuí, as quatro primeiras formadas originalmente em torno de centros missionários. A existência de outras localidades em processo de urbanizaçáo agrava o problema da sustentabilidade ambiental, social e cultural dos povos que habitam este vasto território. Dados recentes indicam que $44 \%$ dos moradores da cidade de São Gabriel da Cachoeira são provenientes de outras localidades da macro-região compreendida pela bacia do rio Negro, sejam povoados ou comunidades ribeirinhas, sejam outros centros urbanos como Santa Isabel do Rio Negro ou Barcelos. Os moradores nascidos na cidade somam $42,6 \%$, enquanto os nascidos em outras regióes do país representam apenas 13,6\% da população urbana. As principais motivaçôes alegadas pelas famílias que saem de suas comunidades para residir na cidade de São Gabriel são a busca por educação escolar, mercadorias e trabalho assalariado (Lasmar 2005). Os dois bairros mais recentes, Dabaru e Areal, abertos nos anos 1980 e 1990, respectivamente, concentram 53\% dos moradores de São Gabriel (ISA/Foirn, 2005).

O surgimento e o adensamento de aglomerados populacionais na regiáo, e o concomitante esvaziamento de comunidades ribeirinhas, devem ser entendidos à luz da longa história de contato das populaçóes indígenas do Alto Rio Negro com os brancos. Essa história, que se iniciou no século XVIII, foi marcada por episódios de escravização, trabalho semicompulsório em piaçabais e seringais, e mais recentemente pela relação sistemática com os missionários salesianos. Entre os anos 1920 e 1970, os salesianos mantiveram um programa de catequese com ênfase na educaçáo escolar de crianças e jovens em internatos localizados nas sedes de missão. Antes dos anos 1960, a área periférica de São Gabriel contava alguns sítios e comunidades de famílias Baré, etnia que ocupava tradicionalmente o território que hoje compreende a cidade. Alguns descendentes de militares e de comerciantes brancos já possuíam um terreno próprio na margem do rio, além da casa principal na cidade.

O processo de adensamento populacional de Sáo Gabriel também foi incentivado por uma série de programas governamentais que visavam a integração geopolítica da região, como o Plano de Integração Nacional (PIN) implementado na década de 70. A militarização da fronteira e as obras de infra-estrutura, ocorridas neste contexto, estimularam a entrada maçica de forasteiros, vindos sobretudo do nordeste brasileiro. O Exército e a Aeronáutica ocuparam largas extensôes de terra a jusante da cidade (margem esquerda), deslocando casas e roças indígenas (figura 2). Paralelamente, militares não-indígenas, comerciantes e garimpeiros não indígenas começaram a se instalar em Sáo Gabriel. A maioria deles obteve um terreno na beira das novas estradas, onde abriram fazendas de gado, enquanto outros se casaram com mulheres indígenas e começaram a explorar terrenos na beira do rio. Uma onda de garimpagem criou um certo temor de que ocorresse uma "invasão" dos brancos e muitas famílias indígenas procuraram legitimar seus direitos fundiários por meio de um título do Instituto Nacional de Colonização e Reforma Agrária (INCRA).

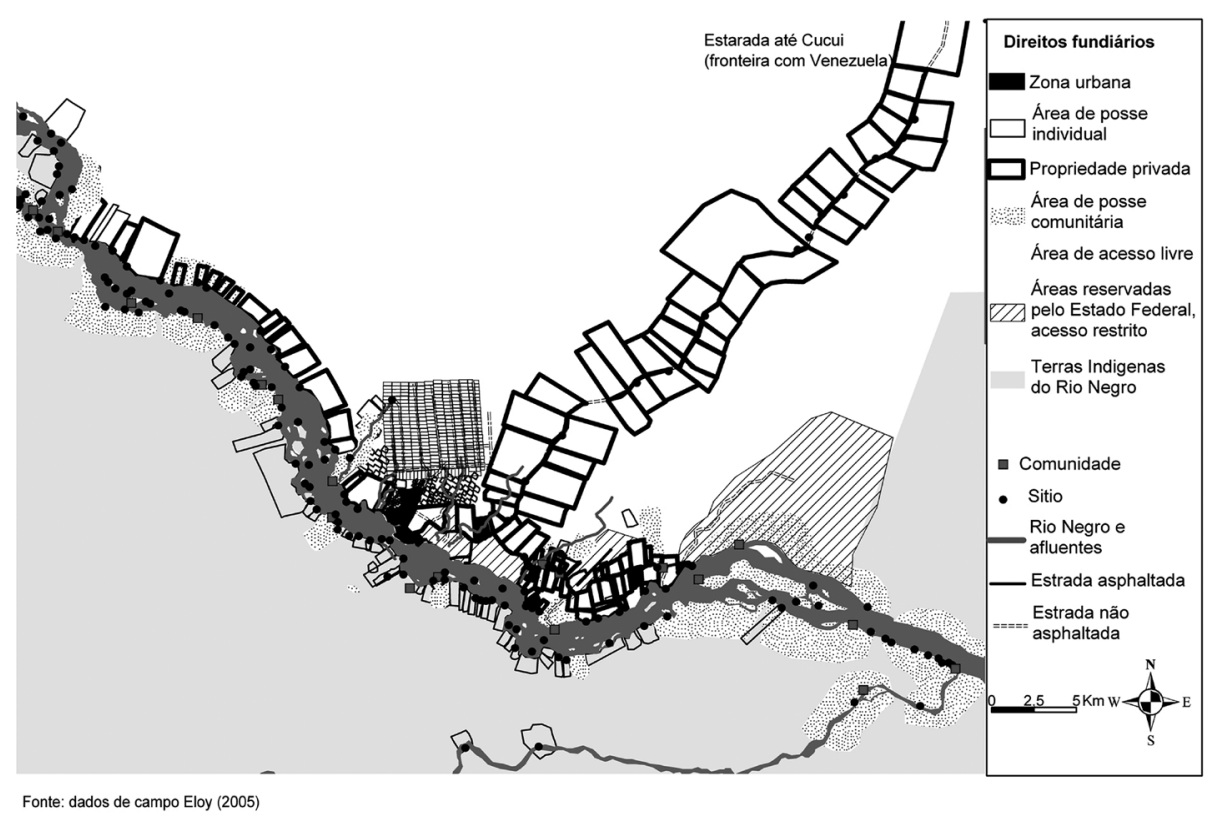

Figura 2 - Direitos fundiários na região de São Gabriel da Cachoeira 
Nessa mesma época, intensificava-se o processo de migração dos índios das comunidades do interior para a cidade. Um fator importante foi o fechamento dos internatos salesianos, no início da década de 80 , e a decorrente necessidade de que as famílias viabilizassem moradia em São Gabriel para que os filhos pudessem completar os estudos. Além disso, a queda no valor dos produtos extrativistas incentivava a busca por um trabalho assalariado. Desse modo, o fluxo migratório a jusante tornou-se um traço marcante da dinâmica sociodemográfica do Alto Rio Negro (Lasmar, 2005).

As famílias indígenas recém-chegadas começaram a abrir roças na beira do rio. Isso explica a presença atual de comunidades pluri-étnicas (cuja população varia entre 30 a 170 habitantes) formadas originalmente apenas por Barés ou por grupos familiares Tukano. Por um breve período, a demanda por terras continuou sendo atendida por meio da distribuição de lotes em um assentamento agrícola criado pela Prefeitura na área setentrional da cidade, em 1995 (Assentamento Agrícola Teotônio Ferreira). Este assentamento corresponde a uma área de $35 \mathrm{~km}^{2}$, dividida em lotes de 10 ha. As famílias beneficiadas obtiveram o direito de uso exclusivo para fins agrícolas, mas a Prefeitura permaneceu proprietária dos terrenos. Atualmente, este assentamento agrícola está localizado entre as grandes propriedades privadas à beira da estrada e as áreas reservadas para União Federal, e tende a se expandir em direção ao Norte (figura 2). Assim, com o passar do tempo e o adensamento da população, os terrenos disponíveis passaram a se situar em áreas muito remotas, obrigando algumas famílias a andar cerca de quatro horas para chegar às suas roças (Eloy, 2008).

$\mathrm{Na}$ margem do rio oposta à cidade, já se localiza a Terra Indígena. Porém, embora os títulos fundiários não possuam mais valor oficial, existem propriedades « funcionais ", ou seja, unidades fundiárias circunscritas onde os bens naturais são apropriados de maneira exclusiva e individual. Na maioria dos casos, as famílias "proprietárias" moram na cidade há mais de vinte anos, e possuem, pelo menos, algum membro (o chefe de família, sua esposa ou os pais/sogros) que se auto-denomine Baré ou Tukano Oriental (Tukano, Desana, etc.). Em geral, eles possuem fonte de renda na cidade (emprego, comércio). A maioria pratica uma atividade produtiva com a "ajuda" de um "vigia". O "vigia", geralmente, uma pessoa aparentada, é autorizado a cultivar as terras do proprietário, através de diversos tipos de acordos, como veremos mais adiante. Podemos dizer que, na região de São Gabriel, e mesmo na Terra Indígena, a urbanização ocorre paralelamente à afirmação da propriedade privada da terra, como em outras regióes da Amazônia (Becker, 1990). Devido a esta tendência, à medida em que nos aproximamos do centro urbano, os territórios das comunidades se tornam reduzidos, fragmentados e/ou estritamente delimitados (figura 2).
A partir dos anos 70, alguns moradores de comunidades antigas passaram a morar na cidade e fizeram questáo de marcar materialmente a separaçáo entre o seu sítio e o resto do território da comunidade, por meio da obtençáo de um título de posse individual. Devido a esses movimentos sucessivos de adesão e separação de famílias, estas comunidades apresentam uma certa heterogeneidade do ponto de vista da sua composição étnica e residencial (uma parte agrupada, uma parte dispersa em sítios). Paralelamente, desde os anos 1980, observamos a criaçáo e o crescimento de comunidades recentes, povoadas principalmente por famílias oriundas da Bacia do Içana (Baniwa e Kuripako) (tabela 1). Esse adensamento populacional de origem recente concentra-se em dois pontos: ao longo da estrada de Camanaus, que liga a cidade ao porto de mesmo nome localizado a jusante, e na margem do rio imediatamente oposta à praia principal da cidade. O grupo de famílias usufrui de um território reduzido e com limites estritamente definidos (menos de $20 \mathrm{ha}$ ), por ser cercado de propriedades individuais. Com alta densidade populacional, esse tipo de comunidade tem seu sistema produtivo condicionado pela exigüidade do território, pela falta de acesso aos recursos pesqueiros e pela degradaçáo da cobertura florestal.

A generalização da propriedade privada como meio de acesso à terra, e a reduçáo do tamanho das comunidades induzem as famílias que se instalam na região de São Gabriel a dois tipos de estratégias: 1) pluriatividade (ou seja, atividade agrícola intensificada e associada com empregos remunerados); 2) acesso indireto à terra. Na discussão que se segue, veremos que a maior parte das famílias combinam as duas estratégias para contornar a escassez de recursos naturais, recriando um sistema de manejo dos recursos naturais baseados na multilocalidade, mobilidade e articulaçáo de direitos fundiários individuais e coletivos.

\section{Incorporando a cidade no sistema indígena de manejo dos recursos naturais}

Embora essas levas migratórias, de que falamos acima, tenham em larga medida determinado o processo histórico de urbanização, não seria apropriado falar em 'êxodo rural', isto é, em um movimento generalizado de transferência definitiva de residência das comunidades para o centro urbano e sua periferia. Os movimentos polarizados pela cidade podem ser tanto definitivos como temporários, reversíveis ou circulares. Apresentam-se combinados com uma mobilidade sazonal entre cidade e floresta, ritmada pelos calendários escolar e agrícola. Mais de um terço dos grupos domésticos que residem na área urbana possuem um ou dois sítios de produção agrícola na zona periurbana. Além disso, 13,5\% das famílias afirmam praticar a caça nos arredores da cidade e $23 \%$ pescam regularmente (ISA/Foirn, 2005). Identificamos três grandes tipos de estratégias produtivas associadas à agricultura familiar 
indígena. A estratégia de pluriatividade e multilocalidade, na qual a familia, que mora a maior parte do tempo na cidade, combina algumas roças (geralmente localizadas em diferentes lugares) com atividades remuneradas, representa $73 \%$ da amostra. A estratégia de auto-suficiência, na qual a familia mora a maior parte do tempo numa comunidade ou num sítio individual, e vive de roça e extrativismo, representa 18\% da amostra. A situação de especialização agrícola para venda de produtos da mandioca no mercado urbano, desenvolvida por famílias que moram perto da cidade mas com área de uso muito reduzida e sem acesso aos recursos pesqueiros, foi encontrada em $9 \%$ dos entrevistados.

Os sistemas residenciais multipolares (ou multilocalidade) que articulam areas rurais e urbanas, já foram descritos em outras regiōes da América latina (Cortes, 1998, Padoch et al., 2008). No caso de São Gabriel da Cachoeira, a prevalência do padrão de multilocalidade associa-se estreitamente ao fato do deslocamento até o centro urbano ocorrer de maneira gradativa. Inicialmente, apenas uma parte do grupo doméstico se muda para a cidade ou para comunidades situadas na área periurbana, até que haja condiçôes propícias para a instalação adequada de todos os membros. A mobilidade circular entre os diferentes sítios de produção permite manter a complementariedade espaço-temporal entre os sistemas de cultivo na paisagem periurbana, o que contribui para a sustentabilidade da agricultura de corte e queima (Eloy, 2008). $\mathrm{Na}$ escala da unidade de produção, a associação de diferentes sistemas agroflorestais contribui para a segurança alimentar, a distribuição eficiente de períodos de trabalho intensivo, e para a conservaçáo da fertilidade e da agrobiodiversidade em condiçôes pedoclimáticas e econômicas altamente variáveis (figuras 4 e 5). Note-se, porém, que, no contexto periurbano, as territorialidades multilocais dependem de arranjos entre indivíduos e famílias, os quais sempre envolvem diversas formas de cessão temporária de direitos fundiários.

No espaço urbano e periurbano, a modalidade-padráo de acesso à terra é a compra do direito de uso exclusivo. Outro meio muito frequente de obtenção de terra é a invasão em caso de ausência prolongada, que representa justamente a negação do direito de propriedade. $\mathrm{O}$ processo de ocupação da zona periurbana criou desigualdades em termos de acesso a emprego e ao capital fundiário (figura 2), que resultam em larga medida do tempo de residência e dos modos de inserção das famílias no sistema social da cidade. De uma maneira geral, os brancos ocupam uma posição privilegiada no sistema social urbano, possuindo mais acesso a atividades remuneradas e, consequentemente, às mercadorias.

A maioria das famílias indígenas que passa a morar na cidade não têm condiçôes, pelo menos num primeiro momento, de adquirir terrenos agrícolas, uma vez que precisa investir na compra de um lote urbano para construir sua casa.
As famílias costumam contornar a dificuldade de obtenção de lotes agrícolas por meio de estratégias de acesso indireto à terra, principalmente através da negociação com parceiros pertencentes à sua rede de parentesco e de conhecidos. Nesse contexto, a aliança matrimonial com branco também representa um meio importante de acesso ao estatuto de "proprietário". As mulheres casadas com branco na cidade costumam possuir terrenos na área peri-urbana e exercem um papel importante no processo de integração das famílias recémchegadas (Lasmar 2005, 2008), uma vez que podem propiciar acesso a mercadorias, à terra e a uma casa de forno perto da cidade. Além das estratégias matrimoniais, encontramos uma grande diversidade de arranjos que propiciam o acesso indireto e temporário aos espaços e recursos. Eles podem mobilizar diversos fatores, tangíveis (alimentação, equipamento, mercadorias) ou intangíveis (prestígio, conhecimento, segurança, serviços). São mais complexos que as relaçóes clássicas de parceria ou arrendamento, merecendo, assim, um estudo detalhado (Lavigne-Delville et al. 2001). Tratamos a seguir dos tipos de concessão que mobilizam os recursos utilizados na produção de alimentos na regiáo de São Gabriel e entorno.

\section{Empréstimo por tempo determinado}

Este arranjo almeja a imediata resolução do problema do acesso à terra. Estabelece uma relaçáo de ajuda mútua e de troca recíproca entre parentes. Uma família "empresta um pedaço" de roça ou de capoeira para que outra, recém-chegada na cidade, possa ter suas necessidades temporariamente satisfeitas.

\section{Estudo de caso 1: Um exemplo de empréstimo por tempo determinado (2003)}

Raimundo Baniwa morava com seus irmãos no sítio Jacaré Posso, abaixo da comunidade de Santa Rosa, no Médio Içana. Em 2002, seu primeiro filho de 19 anos veio morar na comunidade de Nova Vida, na estrada de Camanaus, para estudar em São Gabriel. Em Nova Vida mora o tio de Raimundo, Felipe. Os outros quatro filhos estudavam em Santa Rosa, mas, segundo Raimundo, "não dava mais pois eles tinham que remar mais de uma hora e meia para chegar na escola”. Em março de 2003, Raimundo veio com os outros filhos para Nova Vida, para eles estudarem na comunidade. "Lá, em Jacaré, tem meus irmãos, e minha irmã vai cuidar das nossas roças. Nós vamos voltar para lá durante as férias para fazer farinha. Ainda sobra um pouco daquela que trouxemos ( ...) e meu tio, Felipe, me deu um pedaço da roça dele para que a gente faça nossa farinha, enquanto minha roça daqui está amadurecendo. Para sobreviver, a gente faz artesanato de arumã para vender na cidade". 


\section{Direito de cultivar e colher em troca de trabalho ou produto}

Esse segundo tipo de arranjo se dá entre uma pessoa que possui direito de uso exclusivo sobre um terreno, legitimado através de um título fundiário e/ou do seu poder políticoeconômico, e outra que recebe autorizaçáo para cultivar parte do terreno. Em troca, esta última deve tomar conta da propriedade. Geralmente, o casal proprietário mora na cidade, tem um comércio ou empregos remunerados, e/ou recebe aposentadoria, $\mathrm{e}$ passa os finais de semana e os feriados no sítio. O dono do terreno sempre dá um forno ou uma canoa para o vigia, que costuma lhe oferecer produtos agrícolas. Mas não se trata exatamente de uma parceria no sentido estrito do termo, pois as regras de partilha não parecem claramente definidas nem fixas. $\mathrm{O}$ vigia pode ficar encarregado de abrir as roças do proprietário e zelar pelas árvores frutíferas, enquanto cultiva suas próprias parcelas, colhe fruta, pesca e caça, dentro de certos limites.

A mulher do vigia tem geralmente sua própria roça mas eventualmente pode arrancar mandioca da roça do proprietário, deixando para ele uma parte da farinha. É comum também que um de seus filhos more na casa dos donos do terreno para estudar na cidade. Em alguns casos, o vigia tem que contribuir para o pagamento do imposto anual, se houver.

\section{Estudo de caso 2 : Um exemplo de relação vigia/ dono de terra (2004)}

Maria mora no bairro da praia, em São Gabriel e possui um grande terreno de $3000 \mathrm{~m}$ de largura, na beira do rio, de frente para a cidade. É um terreno que herdou do avô. O título fundiário data do início do século, e o domínio da família sobre a área não foi questionada pela criação da Terra Indígena (1998). Há oito anos atrás, Maria e seu marido autorizaram uma família Baniwa, oriunda no Alto Içana, a abrir suas roças e fundar sua comunidade no terreno. Segundo Maria: "Eu pago para eles abrirem roça para mim.(...) podem fazer roça onde querem (...) quando a gente vem visitá-los, eles costumam oferecer farinha e frutas para nós (...). A beira, do outro lado do rio, não pertence aos índios. Além do limite dos terrenos, aí começa a Terra Indígena”.

\section{Empréstimo de longa duração com restrições de uso}

Neste caso, os direitos de cultivo e colheita dos produtos florestais são concedidos por tempo indeterminado, mas não se pode plantar espécies perenes e construir casa permanente (apenas casa de forno). O dono possui um terreno extenso, próximo à cidade, como é o caso da "terra da Diocese" ou de terrenos de comerciantes politizados, que mantêm a sua influência na cidade através destes "favores". Os produtores costumam então cultivar pequenas parcelas de mandioca, e seus direitos não podem ser transferidos para terceiros sem autorizaçáo do dono.

\section{Migrando para a cidade: diversificação das atividades e dos modos de apropriação dos espaços- recursos}

Se, num primeiro momento, a possibilidade de explorar temporariamente uma roça ou capoeira localizada em terreno de parente ou conhecido que já resida na cidade torna-se um importante meio de sustento alimentar das famílias recémchegadas, com o tempo, a progressiva inserção nas redes sociais locais e a reafirmação de parcerias pode facilitar a obtenção de um direito de uso permanente num terreno individual ou no território de uma comunidade. Mas a adesão a uma comunidade periurbana nem sempre é fácil ou desejada, pois, como já mencionamos, a vida na comunidade implica certas obrigaçóes, como a participaçáo em eventos e trabalhos comunitários. Por isso, muitas famílias recém instaladas evitam recorrer a esse tipo de arranjo, e se esforçam em obter um "terreno próprio", sobretudo aquelas cuja causa imediata do abandono da comunidade de origem foi uma briga ou conflito.

Se o chefe de família náo consegue um terreno pela Prefeitura (no assentamento, ao longo da estrada) pode tornarse "vigia" durante um certo tempo. Alias, é comum que o primeiro filho, instalado na cidade antes dos pais (para fazer serviço militar, casar ou estudar), inicie a negociação. Além de disponibilizar sua casa de forno para os novos ocupantes, o casal proprietário sempre ocupa um papel importante na diversificaçáo do material cultivado da família "vigia" (Emperaire et Eloy, 2008).

Ao longo das trajetórias migratórias, as famílias lançam mão de várias modalidades de acesso indireto à terra. Numa primeira etapa, empréstimos restritos, de curta duração, são combinados com retornos frequentes à comunidade, onde a família ainda possui roças produtivas. Nessa fase inicial de inserção na vida urbana, tornar-se 'vigia 'é uma maneira de utilizar sua força de trabalho com vistas ao acesso a mercadorias e à escolarização dos filhos. Mas, muitas vezes, as relaçóes com o dono do terreno se deterioram e o "vigia" passa a se sentir explorado. A situação desconfortável que se cria entre o "vigia" e o proprietário (fofocas, mal-entendidos) pode levar ao deslocamento das roças ou ao abandono da produção agrícola em favor de empregos remunerados. As relaçóes prévias entre o dono do terreno e o ocupante vão determinar os tipos de troca e a margem de atuaçáo dos parceiros : cooperaçáo (comensalidade e partilha) com parentes próximos, relaçốes assimétricas com parentes mais distantes e instalados na cidade, até a exploração de tipo paternalista.

O nível de monetarizaçáo do arranjo e sua flexibilidade refletem os tipos de relaçóes envolvidas na troca de direito de uso. Em suma, frente à falta de disponibilidade dos terrenos cultiváveis perto da cidade, as famílias indígenas procuram diversificar espacialmente os direitos de uso e as modalidades de parceria, o que permite aproveitar recursos naturais, renda $\mathrm{e}$ 
a mão de obra familiar. Na figura 3, exemplificamos como uma familia articula diversos direitos fundiários, e, desta maneira, compóe uma territorialidade multilocal onde os diferentes sítios de produção e de moradia se complementam.

Em suma, se, por um lado, a propriedade privada (legal ou funcional) é o regime fundiário dominante nos arredores da cidade, por outro, os migrantes se valem de múltiplos arranjos para garantir acesso aos recursos naturais. Na zona periurbana, apesar da existência de desigualdades nos direitos fundiários, a multilocalidade, a mobilidade e os arranjos familiares para troca de direitos fundiários ajudam as famílias a acessar áreas de cultivo e de floresta, bem como produtos de caça e pesca (figura 4). A estratégia da multilocalidade pode ser entendida, portanto, como uma manifestação da adaptabilidade dos sistemas tradicionais de manejo dos recursos naturais.

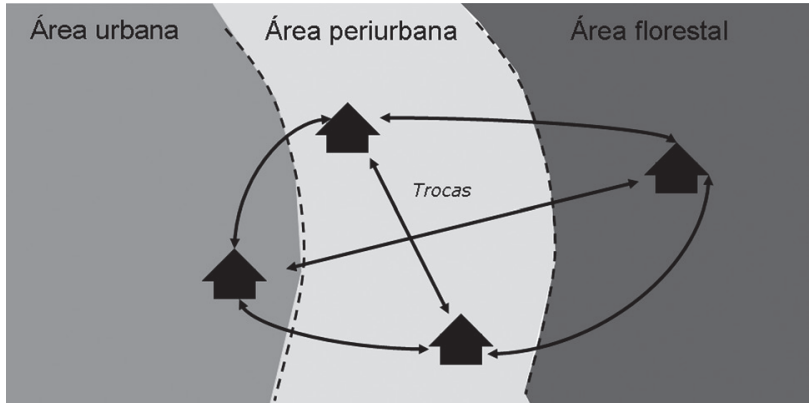

Figura 4 - Multilocalidade e mobilidades circulares (grupo doméstico ou familia extensa)

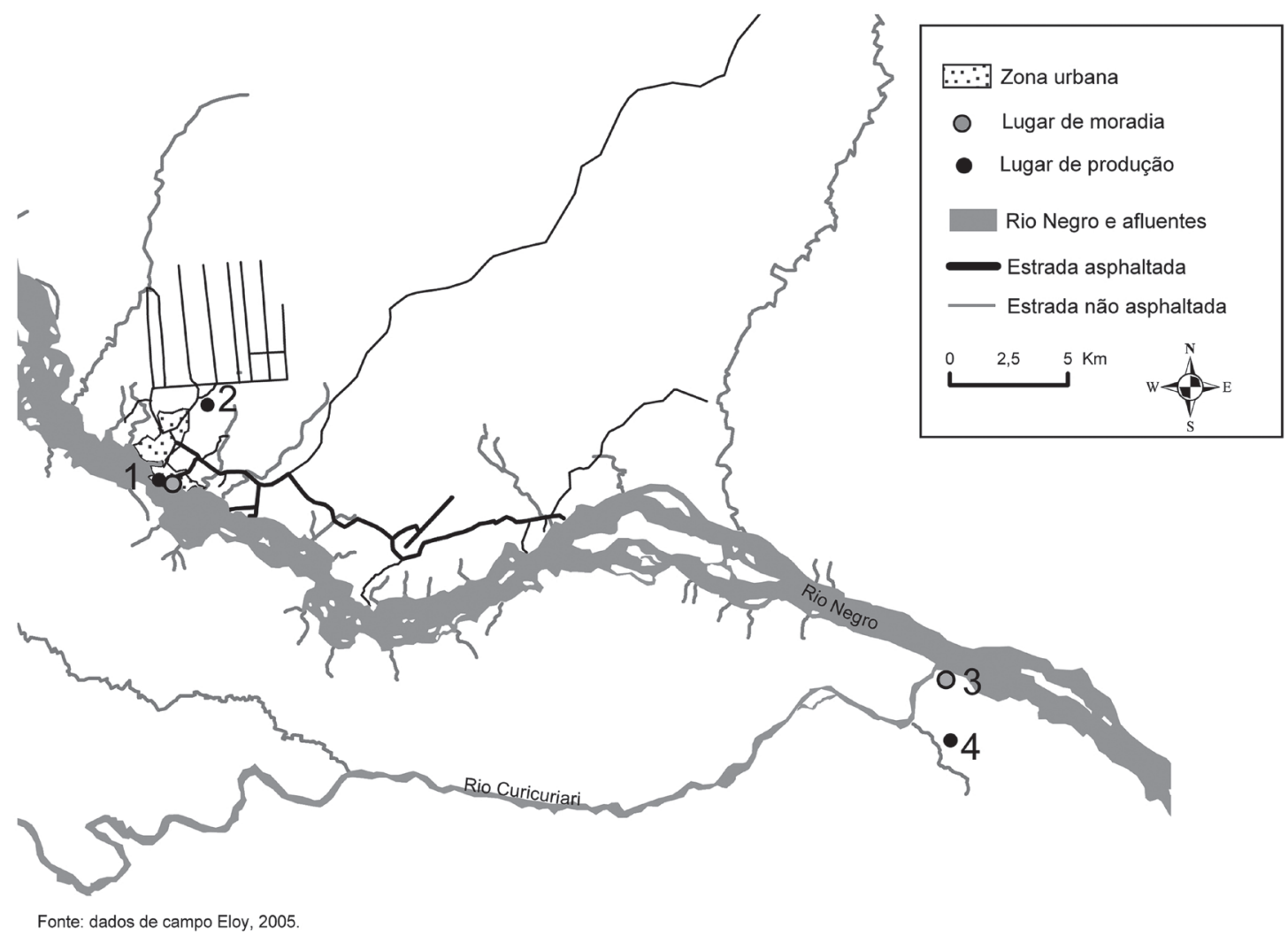

Figura 3 - Recriação de uma territorialidade multilocal no espaço periurbano.

Exemplo de uma familia falante Tukano que mora na cidade de São Gabriel da Cahoeira, e possui três sitios de producão. 0 sitio mais proximo (1), 0 quintal, é usado diaramente (terreno privado), o sitio na saida da cidade (2) é uma roça de capoeira explorada nos finais de semana (posse sem titulo), e o sitio mais remoto (3) é explorado durante as férias escolares (direito de uso temporario no terreno de uma comunidade). E um lugar onde, além de poder fazer grandes roças de mata virgem, se pode também aproveitar a pesca, caça e fibras da floresta. 


\section{Conclusão: territorialidades indígenas e redes sociais entre cidade e floresta}

Nas regióes de florestas tropicais e, sobretudo na Amazônia, a oposição conceitual entre cidade e floresta remete imediatamente a dois regimes principais de apropriação de recursos naturais e terras: a propriedade privada de um lado, e o usufruto coletivo do outro. De fato, estas normas induzem transformações na composição e nas funçôes atribuídas às parcelas cultivadas e às capoeiras. No Alto Rio Negro, a migração floresta-cidade leva em geral à dispersáo dos exhabitantes de uma mesma comunidade e à intensificaçáo do processo de atomização das famílias. Em São Gabriel, a família nuclear (o casal e seus filhos) passa a ser a unidade relevante do ponto de vista sociológico (Lasmar, 2005). Além do mais, a roça adquire um sentido cada vez mais instrumental e econômico na cidade, declinando sua importância enquanto fonte de identidade feminina e coesão coletiva.

No entanto, as famílias indígenas residentes no contexto urbano articulam diferentes locais de vida e modalidades de apropriação dos recursos naturais, aproveitando os direitos fundiários adquiridos ao longo da trajetória migratória. As estratégias famíliares de diversificaçáo atendem a objetivos simultâneos: segurança alimentar e obtenção de mercadorias, e também a capitalização fundiária ao redor de uma residência urbana relativamente fixa. Assim, a legitimaçáo crescente da propriedade privada associada ao processo de urbanizaçáo não induz a uma dinâmica linear de individualização mas a uma reproduçáo do sistema indígena de manejo dos recursos naturais na escala de uma unidade familiar mais restrita (o grupo doméstico ou a familia extensa).

Podemos dizer, portanto, que o processo de urbanização no Alto Rio Negro se baseia em um sistema complexo de acesso aos recursos que se associa diretamente a um padrão multilocal de organização das atividades produtivas entre cidade e floresta. Adotando uma perspectiva que nos leva além de uma dicotomia rígida entre cidade e floresta, nossa conclusão é que a estratégia multilocal de produção e criação de espaços de vida pode ser vista como uma manifestação importante da resiliência das territorialidades indígenas. As inovaçóes decorrentes podem configurar um novo e complexo tipo de manejo de recursos naturais.

\section{Notas:}

1. 'Área peri-urbana` refere-se a uma área de transição ou interação na qual atividades urbanas e rurais são justapostas e a paisagem está sujeita a modificaçôes rápidas induzidas pela atividade humana (Douglas, 2006).

2. O regime de propriedade comum (common property) diz respeito a situaçôes onde o recurso é possuído e controlado por uma comunidade de usuários identificável, e cujo manejo requer regras e decisões coletivas. Geralmente, trata-se de áreas usadas de maneira menos intensiva, mais remotas e sem limites claros (Berkes, 1989).

3. Entendemos a adaptabilidade como a capacidade dos atores em influenciar a resiliência de um sistema, isto é, "a capacidade do sistema em absorver uma perturbação e reorganizer-se, mantendo suas funçôes, identidade, estrutura e efeitos essenciais" (Walker et al., 2004).

\section{AGRADECIMENTOS}

As pesquisas que resultaram neste artigo foram apoiadas financeiramente pelo CNRS, o IRD, o CNPq e realizadas em parceria estreita com o Instituto Socioambiental e a Federação das Organizaçóes Indigenas do Rio Negro. Agradecemos à equipe do programa Rio Negro do ISA, a Philippe Lavigne-Delville (GRET) e Alain Karsenty (CIRAD), pelos comentários às versóes anteriores, e às famílias Tukano, Tariano, Dessana, Pira-Tapuya, Wanano, Baniwa, Kuripako e Baré, pelo acolhimento e envolvimento durante o trabalho de campo.

\section{REFERÊNCIAS BIBLIOGRÁFICAS}

Adams, C.; Murrieta, R.S.S.; Neves, W.A. 2006. Amazonian Caboclo societies: modernity and invisibility. São Paulo, Annablume, 362 pp (text in Portuguese).

Albert, B. 2000. Sustainable Indigenous Associations and Sustainable Development in the Brazilian Amazonia. In: Ricardo, C. A. (Ed.) Indigenous Peoples in Brazil, 1996-2000. São Paulo, Instituto Socioambiental: 197-207 (text in Portuguese).

Alcorn, J., and V. M. Toledo. 1998. Resilient resource management in Mexico's forest ecosystems: the contribution of property rights. In : F. Berkes and C. Folke (eds). Linking social and ecological systems. Cambridge University Press, Cambridge: 216-249.

Andrello G. 2006. Cidade do indio. Transformaçôes do cotidiano em Ianaretê, São Paulo : Unesp, 448 p.

Becker, B. 1990, Amazonia, São Paulo: Ática, 112 pp (text in Portuguese).

Berkes F. (ed). 1989. Common Property Resources: Ecology and Community-Based Sustainable Development. Belhaven Press, London, $302 \mathrm{pp}$.

Browder, J. O.; Godfrey, B. J. 1997. Rainforest Cities. Urbanization, Development and Globalization of the Brazilian Amazon. New York, Columbia University Press, $424 \mathrm{pp}$.

Chernela, J. 1993. The Wanano indians of the Brazilian Amazon: a sense of space. Austin, University of Texas, $185 \mathrm{pp}$.

Cortes, G. 1998. Migrations, systèmes de mobilité, espaces de vies: à la recherche de modèles. Espace géographique 27(3): 265-275.

Cunha, M. C. d.; Almeida, M. W. B. 2001. Traditional populations and environmental conservation. In: Capobianco, J. P. R. (Ed.) Biodiversity in the Brazilian Amazon region: evaluation and priority actions for conservation, sustainable use and sharing of benefits.. São Paulo, Instituto Socioambiental / Estação da liberdade: 184-193 (text in Portuguese). 
Douglas, I. 2006. Peri-urban ecosystems and societies transitional zones and contrasting values. In: McGregor, D. Simon, Thompson, D. (eds). Peri-Urban Interface: Approaches to Sustainable Natural and Human Resource Use, Earthscan Publications, London, UK.

Eloy $_{2}$ L. 2008. Resilience of indigenous systems of shifting cultivation in the context of urbanization in north-western Brazilian Amazon. Confins, $\mathrm{N}^{\circ} 2$ (text in Portuguese). [on line]

Eloy, L.; Lasmar, C. 2006. Urbanization in the upper Rio Negro: the sociocultural dynamics at play and agricultural. In: Ricardo, F., Ed. Povos indígenas no Brasil 2001-2005. Instituto Socioambiental, São Paulo (text in Portuguese).

Eloy, L. ; Le Tourneau, F. M. 2009. Does urbanization causes the deforestation of Amazonia? Territorial and agricultural innovations in north-western Amazon (Brazil)? Innovations territoriales et agricoles dans le nord-ouest Amazonien (Brésil). Annales de Géographie, 667 : 204-227 (text in French).

Emperaire L., Eloy L. 2008. The city, a center of agriculture in the Rio Negro? Boletim do Museu Paraense Emílio Goeldi, Ciências Humanas, Belém, 3 (2): 195-211 (text in Portuguese).

Freire, G. (2003). Tradition, change, and land rights: land use and territorial strategies among the Piaroa. Critique of Anthropology 23(4): 349-372.

Gallois, D. T. 2004. Inhabited land? Territories? Territoriality? In: Ricardo, F. (Ed.) Indigenous lands and protected areas: the challenge of overlapping. São Paulo, Instituto Socioambiental (Text in Portuguese).

Hugh-Jones, C. 1979. From the Milk River: spatial and temporal processes in the northwest Amazonia. Cambridge University Press, Cambridge, UK, 332 pp.

ISA/Foirn. 2005. Socioeconomic and demographic enquiry of the city of São Gabriel da Cachoeira: results. São Gabriel da Cachoeira, 25 p. (text in Portuguese)

Lasmar, C. 2005. Back to the Milk River: gender and transformation in the upper Rio Negro.Ed UNESP/ISA/NuTI, Rio de Janeiro, $285 \mathrm{pp}$.

Lasmar, C. 2008. Sisterto an Indian, wife to a white mean: female perspectives in the Upper Rio Negro. Revista Mana, Rio de Janeiro, 14: 429-454 (text in Portugueses, with abstract in English).

Lavigne-Delville, P., Toulmin, C., Colin, J.-P., et al. (Eds) 2001. Access to land by the procedures of delegation (rural West Africa): patterns, dynamics and challenges. GRET-IRD- IEED, Paris, 207 $\mathrm{p}$ (text in French).
Meira, M. 1997. Indians and whites in the black waters. Stories of the Rio Negro. Indigenous Peoples of Rio Negro Seminar: Land and Culture. FOIRN, Manaus (text in Portuguese).

Moreira, E. L. 2003. Amazonia in Motion: Networks and Pathways for Development of the Ye'kuana, Roraima. Cadernos de Campo (USP), Volume 11(text in Portuguese, with abstract in English).

Ostrom, E., Gardener, J.; Walker, J. 1994. Rules, Games \& Common Pool Resources. The University of Michigan Press, Ann. Arbor, $369 \mathrm{pp}$.

Padoch, C; Brondizio, E.; Costa, S.; Pinedo-Vasquez, M.; Sears, R. \& Siqueira, A 2008. Urban Forest and Rural Cities: Multi-Sited Households, Consumption Patterns, and Forest Resources in Amazonia. Ecology and Society 13(2). [online]

Pereira, S. A.; Fabré, N. N. 2009. Use and management of territory in areas with open acess in Amazonas, Brazil. Acta Amazonica, 39 (3): 561-572 (text in Portuguese, with abstract in English).

Pezzuti, J.; Chaves, R. P. 2009. Ethnography and natural resources management by the Deni Indians, Amazonas, Brazil. Acta Amazonica, 39 (1): 121-138 (text in Portuguese, with abstract in English).

Redford K.; Stearman A. 1993. Forest-dwelling Native Amazonians and the Conservation of Biodiversity: Interests in Common or in Collision? Conservation Biology 7(2): 248-55.

Ribeiro, B. G. 1995. The Indians of the black waters: mode of production and productive equipment. Companhia das Letras, Edusp, São Paulo (text in Portuguese).

Sahlins, M. 1997. "Sentimental pessimism" and ethnographic experience: or, why culture is not a disappearing "object". Revista Mana, 3 (1): 41-74 (text in Portuguese).

Sirén, A. H. 2007. Population Growth and Land Use Intensification in a Subsistence-based Indigenous Community in the Amazon. Human Ecology, 5(6): 669-680.

Schlager, E. ; Ostrom, E. 1992. Property-rights regimes and natural resources: a conceptual analysis, Land Economics, 68 (3): 249262.

Toledo, V. M., B. Ortiz-Espejel, L. Cortés, P. Moguel, and M. D. J. Ordońez. 2003. The multiple use of tropical forests by indigenous peoples in Mexico: a case of adaptive management. Conservation Ecology 7(3): 9. [on line]

Walker, B., C. S. Holling, S. R. Carpenter, and A. Kinzig. 2004. Resilience, adaptability and transformability in social-ecological systems. Ecology and Society 9(2): 5. [on line]

Recebido em 25/05/2010

Aceito em 07/06/2010 
